\title{
ESP pedagogy: Blending low and high order thinking
}

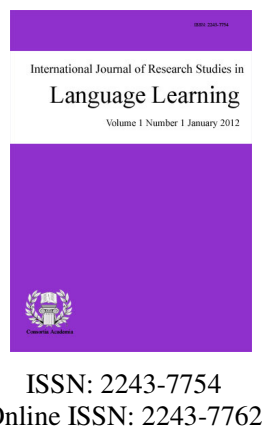

Yuvienco, Janette Custodio

National Taiwan University, Taiwan (janyutw@yahoo.com)

Received: 23 March 2012

Available Online: 31 May 2012

Revised: 14 May 2012

DOI: $10.5861 /$ ijrsll.2012.111
Accepted: 29 May 2012

OPEN ACCESS

\section{Abstract}

Conventional teaching of English has followed a gradual and linear procedure of learning -from vocabulary to phrase to sentence to paragraph. We are familiar with classroom situations where the teacher starts with lecturing about the target language: Firstly, going through a list of vocabulary, then translating words; singling out phrases where a word may be used, then, reading a sentence where the words may be used; finally, walking students through paragraphs, slowly and carefully explaining the grammatical and contextual information in them. In the present Techo-Info Age, however, this approach to learning may prove irrelevant given the amount of information we see, read and hear in different parts of the world at varying contexts and at distinct phases of the development of the language. This paper reports a study on Technology-based pedagogy; it describes and defines the elements of Genre-based pedagogical framework, an ICT-supported set of procedures of teaching Business English at Higher Education which includes showcasing, highlighting, transferring, in order for students to notice, compare and integrate - cognitive skills that encompass both low and high order thinking. Adopting Fink's (2003) instructional procedures and taking into account Schmidt's (1990) Noticing Hypothesis; the framework identifies three aspects of consciousness within language learning: awareness, intention and knowledge thus, seeking to arrive at significant, deliberate learning. Guided by this principle, the last section of the paper proposes a proto-syllabus (Breen, 1989) which elaborates the components of a Business English course. Intermeshing knowledge and skills into teaching, the proto-syllabus contains the following: (1) authentic materials which include genre-specific resources (e.g., writing training course leaflet, writing press release, etc.) and straightforwardly demonstrate the elements of commercial documents and the criteria for evaluating integrated works [projects]; and (2) a glossary of meta-cognitive skills which enables students to know the processes of completing creative tasks for a specific context. These elements predict to aid students to become independent learners and catalysts for continuous, equitable learning in their present learning community and beyond, specifically in their future workplace.

Keywords: ICT-supported learning; genre-based pedagogy; cognitional hierarchy; proto-syllabus 


\section{ESP pedagogy: Blending low and high order thinking}

\section{Introduction}

Conventional teaching of English has followed a gradual and linear procedure of learning -from vocabulary to phrase to sentence to paragraph. We are familiar with classroom situations where the teacher starts with lecturing about the target language -firstly, going through a list of vocabulary, then translating words; singling out phrases where a word may be used, then, reading a sentence where the words may be used; finally, walking students through paragraphs, slowly and carefully explaining the grammatical and contextual information in them. In the present Techo-Info Age, however, this approach to learning may prove irrelevant given the amount of information we see, read and hear in different parts of the world at varying contexts and at distinct phases of the development of the language.

This paper reports a study on Technology-based pedagogy; it describes and defines the elements of Genre-based pedagogical framework, an ICT-supported set of procedures of teaching Business English at Higher Education which includes showcasing, highlighting, transferring, in order for students to notice, compare and integrate --cognitive skills that encompass both low and high order thinking. In adopting Fink's (2003) instructional procedures and taking into account Schmidt's (1990) Noticing Hypothesis, the framework identifies three aspects of consciousness within language learning: awareness, intention and knowledge thus, seeking to arrive at significant, deliberate learning. Guided by this principle, the last section of the paper proposes a proto-syllabus (Breen, 1989) which elaborates the components of a Business English course. Intermeshing knowledge and skills into teaching, the proto-syllabus contains the following: (1) authentic materials which include genre-specific resources (e.g., writing training course leaflet, giving product presentation, writing press release, etc.) straightforwardly demonstrate the elements of commercial documents and the criteria for evaluating integrated works [projects] and (2) a glossary of meta-cognitive skills which enables students to know the processes of completing creative tasks for a specific context. These elements predict to aid students to become independent learners and catalysts for continuous, equitable learning in their present learning community and beyond, specifically in their future workplace.

From the perspective of reflective teaching in ELT, this paper also offers a discrete illustration of a particular pattern of Post-method condition (Kumaravadivelu, 1994) characterized by a reflective approach to teaching which seeks to analyze and evaluate one's own teaching practice --to theorize from one's practice (not without adequate conceptual underpinnings based on "current theoretical, empirical and pedagogic insights" (Kumaravadivelu, 1994, p. 31), and practice what one has been theorized, converting classroom interactions into an ICT-supported research-teaching model. In disclosing an individual emerging reflective teaching strategies (which range from exploring ways and techniques of grappling with course management, experimenting in class, listening to colleagues' advice, reviewing literature on various teaching-learning issues, collaborating on projects with peers, to drafting pedagogical discoveries), this paper concurrently serves as a teacher development resource which adds to Murphy's list of ways of growing as professionals: "gaining teaching experience, participating in teacher-development courses, thinking about and discussing published scholarship, attending conferences, consulting colleagues, getting to know students better" (Murphy, 2001, p. 499).

\section{Noticing Hypothesis \& Deliberate Learning}

Schmidt (1990), in proposing the Noticing Hypothesis, underscores that the emergence of knowledge (e.g., of knowing a new form -in a target language--of a concept) is preceded by something being noticed in the input. Noticing is so crucial in learning that unattended the material is lost; if it is noticed, it becomes intake, whether a learner deliberately attends to a linguistic form in the input, or if it is noticed purely unintentionally. Learning definitely calls for consciously apprehending and being aware of input - "what learners notice in input is what 
becomes intake for learning" (Schmidt, 1995, p. 20).

Schmidt's three aspects of consciousness --awareness, intention and knowledge-- redound to the capacity of students to notice, compare and integrate: the totality of a set of learning processes that demonstrate Deliberate Learning. Attending to the input (noticing), learners evaluate the value of the input, or the learning goal at hand, in relation to a target system (comparing); finally, after having determined the relevance of the input, they incorporate the input into a new form of knowledge (integrating).

Ellis (1997, p. 119) proposes a model which clarifies Schmidt's hypothesis and the place of Noticing in second language acquisition.

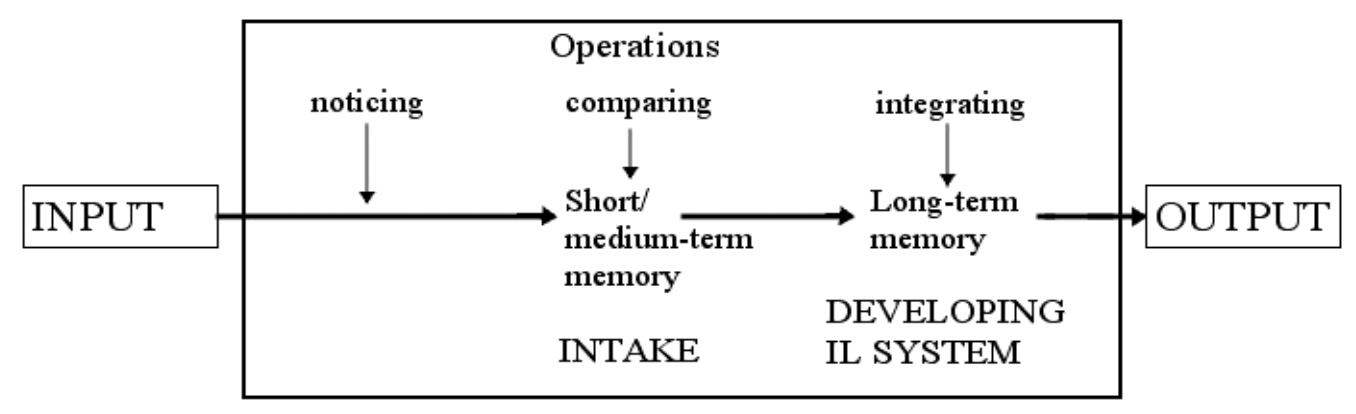

Figure 1. Process of learning

\section{Genre-based Pedagogy}

From the perspective of Deliberate Learning, the Genre-based pedagogy provides the mode which allows for a kind of learning that transcends Bloom's original taxonomy of education: it addresses the six levels of thinking organized hierarchically according to cognitive complexity (Bloom, 1956) yet, goes beyond it. While an input triggers students' various aspects of consciousness (awareness, intention and knowledge) at each level of cognition, teachers, in employing a Genre-based pedagogy, guide learners' learning in a scaffold manner: proceeding from the lowest level of cognition (identification/recall) to the highest level (creation). (This pattern of interaction between the teacher and the students exemplifies an educational hierarchy endorsed by Anderson and Krathwohl (2001) who, after revisiting Bloom's taxonomy of education, reckon that learning peaks not so much at evaluation, as at creation.) This pedagogical framework is characterized by a close connection with the human dimension, e.g., "learning how to learn, leadership and interpersonal skills....communicational skills, character....ability to adapt to change" (Fink, 2001, p. 29).

A framework of language teaching (with repercussions for learning and assessment) that explores language and its role in the social construction of experience, Genre-based pedagogy draws upon the functionality of language theorized in terms of three meta-functions (Christie, 1999: p. 759-760): the ideational, which deals with the experiences represented or constructed within language; the interpersonal, which deals with the nature of the relationships of persons in using the language; and the textual, which deals with the organization of language as coherent messages. Concretely, it provides teachers and students a shared code: a principled way to focus on and identify what is to be known and accomplished (e.g., vocabulary, discourse, features of target ICT-supported creative projects [such as, leaflet, press release, etc.]; participants of communication [i.e., the target audience of the project]; structure of target creative projects), resulting in not so much a simple "transmission" of concepts and an unimpressionable learning, as a constructive and interactive experience of and within the language.

Most importantly, the Genre-based pedagogy draws on the principles of Post-method Condition which attempts at arriving at a "systematic, coherent, and relevant alternative to method that is informed by principled pragmatism" (Kumaravadivelu, 1994, p. 31), one that is based on pragmatics of pedagogy (Widdowson, 1990) and which provides adequate conceptual underpinnings based on "current theoretical, empirical and pedagogic insights" (Kumaravadivelu, 1994, p. 31). It illustrates a "codified but flexible set of reiterated procedures for 
Yuvienco, J. C.

participants to conduct research in their own settings" (Bailey, 2001, p. 491).

In summary, the Genre-based pedagogy is a research-oriented pedagogical framework which originates from action-based research (McNiff, Lomax, \& Whitehead, 2003); in fostering collaborative work among teachers, students, researchers, administrators and ICT-based material providers, it examines (predominantly) the cognitive hierarchy of learning which occurs in second/foreign language acquisition.

\section{Cognitive Levels and Significant Learning}

Within the Genre-based pedagogy, which from here on is referred to as GP framework, learning at the higher levels is dependent on having attained knowledge (and skills) at the lower levels. Thus, aiming at creation, (e.g., completing a Product Presentation) for instance, students acquire a basic knowledge of something (e.g., features of a cell-phone) before they are able to create a new set of knowledge (e.g., modified product) required by a specific context and called for by humanistic standards.

The following paragraph enumerates the set of calibrated learning processes which begins at recall (the lowest level of knowing) and ends at creation, e.g., designing a new model of a cell-phone (the highest level of knowing which takes into consideration a kind of lasting change that is relevant to the learner: connecting ideas, people and realms of life.

At the lowest level-Recall Level- students identify specifics about the target learning objective (e.g. basic knowledge of features of a product). At the next higher level -Understand Level- they demonstrate comprehension by giving descriptions (e.g., elaborating relation of features with each other). These two levels correspond to the Foundational Knowledge category in the taxonomy of significant learning which provides the basic understanding necessary for other kinds of learning to take place. At the third level -Apply Level—students use a set of knowledge in a real, concrete and distinct situation (e.g., use of cell phone to the elderly/kids); at the fourth level -Analyze Level—students analyze solutions to problem/s that arise from the application of a set of knowledge; at the fifth level -Evaluate Level- students evaluate the best solution. These three levels correspond to the Application category in the taxonomy of significant learning, which allows other kinds of learning (e.g., critical, creative) to become useful. Lastly, at the sixth level -Create Level—students design or construct a plan (or a model) to complete a new creation which addresses a set of specific problem/s. It relates with the Integration category in the taxonomy of significant learning which, in allowing for making new connections, empowers students, both intellectually and emotionally, to learn about oneself and others (Human Dimension), to develop new interests and values (Caring) and be aware of how to recreate or repeat the project in another instance thus, becoming self-regulated learners (Learning how to Learn).

The figure below shows the distinct cognitive levels within Bloom's taxonomy of educational objectives which relate to the major categories in the taxonomy of significant learning (Fink, 2001, p. 30).

\begin{tabular}{|c|c|}
\hline Cognitive Level & Significant Learning \\
\hline Remember & Foundational Knowledge \\
\hline Understand & Application \\
\hline Apply & \\
\hline Analyze & Integration \\
\hline Evaluate & Human Dimension \\
\hline \multirow{2}{*}{ Create } & Caring \\
& Learning how to learn \\
& \\
&
\end{tabular}

Figure 2. Cognitive Levels and Significant Learning

\section{Codified Teaching Processes}

Schmidt (1990) identifies five factors that constrain Noticing: expectations, which deal with events which 
are not noticed if they are either uninterpretable in the current context or so stable as to be part of the context; frequency, which deals with the frequency of recurrence of items; perceptual salience, which deals with phonological issues (e.g. phonologically reduced morphemes: contracted and unstressed) are less likely to be noticed); skill level, which deals with routinization of previously learned skills; and task demands, which deal with the relevance of information with the required task. In view of this, Genre-based pedagogical framework capitalizes on three basic teaching processes that align with Noticing: showcasing, highlighting, and transferring.

Showcasing entails setting a situation which allows for the best features of an input to be seen. Within the GP framework, the teacher demonstrates the distinctness of a text or speech by presenting a genre (e.g., communication genre: press release, course leaflet, company profile, product presentation) characterized by textual regularities (Giltrow, 1995: Giltrow \& Valiquette, 1994) thus, conveying a particular, specific style and inducing awareness, an aspect of consciousness that arises at the Noticing level.

Students do not easily capture the distinct characteristics of a genre, despite its particularity; Highlighting draws students' attention to the typical elements which constitute the communication genre. It allows for easy recognition of difference/s between them and leads students to arrive at the Intention aspect of consciousness (comparing). Finally, Transferring allows students to apply new forms of knowledge to a new personal context, enabling students to store them in long term memory (integrating).

The figure below gives a summary of the teaching processes that align with (or correspond to) the learning processes which lead to the three aspects of consciousness: awareness, intention and knowledge.

\begin{tabular}{|c|c|c|}
\hline Teaching Processes & Learning Processes & Consciousness \\
\hline Showcasing & Noticing & Awareness \\
\hline Highlighting & Comparing & Intention \\
\hline Transferring & Integrating & Knowledge \\
\hline
\end{tabular}

Figure 3. Teaching-learning Processes and Consciousness

\section{ICT-supported Teaching and Learning}

As a support for pedagogical procedures, the ICT-based tools within the GP framework allow teachers to showcase, highlight and transfer knowledge, while they aid students to notice, compare and integrate knowledge: these tools facilitate interactions between the teacher and students and among the instructor, facilitator and the students (Yuvienco, 2010). Yet, more importantly, they also aid ICT-supported teaching and research: they allow "visiting" teachers to have access to the pedagogical events and offer formative feedback on the teaching-learning processes (the teachers and students' actions and interactions during the course), resulting in an opportunity for multiple perspectives and learner involvement (Murphy, 2001). Heeding advice about strategizing framework for interactive L2 teaching and in line with facilitating low and high thinking skills, the following section identifies and defines the ICT-based tools that are relevant to strategic teaching and research within an ICT-supported GP framework. These ICT-based tools, in facilitating not only self-observation and self-assessment, but also peer-observation and peer-assessment, demonstrate HOW certain macro-strategies (Kumaravadivelu, 1994) ${ }^{1}$ are made operational in Genre-based pedagogy.

\subsection{Announcement}

A delivery tool, the Announcement gives -most primarily during the Familiarization phase of Blended

\footnotetext{
${ }^{1}$ Kumaravadivelu (1994) enumerates 10 macro-strategies (general plans) derived from theoretical, empirical, and pedagogical knowledge related to L2 learning and teaching, that consist a strategic framework for L2 teaching: maximize learning opportunities, facilitate negotiated interaction, minimize perceptual mismatches, activate intuitive heuristics, foster language awareness, contextualize linguistic input, integrate language skills, promote learner autonomy, raise cultural consciousness, and ensure social relevance.
} 
Learning within foreign language education ${ }^{2}-$-new information about topics and tasks, the Subject Heading of which may be labeled either New when the contents contained therein are intended to familiarize students with, as yet, unknown information; or Important when the information delivered is intended to provide additional or further information. Materials contained herein include directives, instruction about how tasks are completed; pronouncements of guidelines, suggestions and general assessment of projects. It allows relevant files to be attached and URL (Uniform Resource Locator) details, with brief description, to be indicated.

The Announcement provides a space for students to come in contact (through authentic communications from the teacher) with instances of simultaneous integration of syntactic, semantic, pragmatic and discourse phenomena, instead of isolated, discrete items (e.g., list of vocabulary, phrases, rules of grammar, etc.).

\subsection{Course Info}

A delivery tool, it provides basic information about the course such as, the course name, course description, objectives, assigned readings and reference books, evaluation procedures and contact details of the Facilitator/s. As a component of the Familiarization phase, it familiarizes the students with the general features of the course, preparing them psychologically for the demands of the course.

In delineating information that seek to reduce perceptual mismatches originating from pedagogic, procedural, instructional, attitudinal, and evaluative sources (Kumaravadivelu, 1991), the Course Info diminishes mismatch between teacher intention and learner interpretation (or between teacher talk and student listen).

\subsection{Course Content}

A delivery tool employed at the Familiarization phase, it offers a detailed list of the subjects/topics covered in each week; it allows relevant files, which include models of learning (e.g., speaking/writing genre) to be attached. Like the Course Information, in delineating information that seek to reduce perceptual mismatches originating from pedagogic, procedural, instructional, attitudinal, and evaluative sources (Kumaravadivelu, 1991), the Course Content diminishes the mismatch between teacher intention and learner interpretation.

\subsection{Forum}

A discussion tool, it enables learners to confer with the members of the class about Instructor-initiated topics at the start of the discussion of a topic and the completion of a task; also, when students have arrived at the Planning phase when they need to design and arrange the elements of their task; and most especially when they at their peak of completing the task at the Performance (Execution) phase, a point in the learning cycle, time when they need some clarifications and/or explanations to remain focused and gather some encouragement. It keeps a record of the number of posted messages and the replies to them, as well as an elaboration of their thoughts and ideas about the subject matter.

The Forum characteristically facilitates negotiated interaction, an activity that engages learners in the presentation of their own thoughts, feelings and ideas, in posing questions and answering them and commenting others' feedback and suggestions. This interaction generates meaningful exchanges among the participants (Brock, 1986.)

\subsection{Resources}

An interactive tool, it familiarizes students -at the Familiarization phase--to resources (e.g. websites, books and articles) that are useful for designing and completing their tasks at the Planning phase, as well as their peers'. It also enables students to contribute useful resources, with brief descriptions, for tasks and expand their peers'

\footnotetext{
${ }^{2}$ Blended Learning within Foreign Language Education distinguishes seven phases of learning: Familiarization, Planning, Execution,
} Assessment, Strategy Formulation, Action Revision and Final Appraisal (Yuvienco, 2007). 
ESP pedagogy: Blending low and high order thinking

and their own sources of information. It allows connection through e-mail with the contributors, which facilitate further interaction.

The Resources offer a space for teachers, upon treating class activities as a social event jointly constructed by teachers and learners (Breen, 1985), to create learning opportunities and to utilize learning opportunities created by learners.

\subsection{Assignment}

A delivery tool, it indicates the how of completing an assignment: it specifies the type of assignment (e.g., group or individual), the mode of submission (e.g., online, paper-based), the percentage of the task and the due date which automatically shuts down and blocks late submission. It most importantly gives access to examples of Great Assignment, which serves as basis for comparison between their own works and their peers'.

The features of the Assignment allows for developing strategies that promote learner autonomy (Yuvienco, 2006) which includes meta-cognitive strategies, the skills for planning one's own learning; and cognitive strategies, the skills for comparing and analyzing information.

\subsection{Poll}

An interactive tool, it gathers feedback from learners on course and learning satisfaction, and their own learning progress, in relation to the facilitator's support. Similar to an opinion poll, it asks questions to determine what students think about a subject, which allows negotiation between the students and the teacher to take place and fosters the change of power distribution pattern and development of interdependent autonomy (Aoki, 2005). It consists of Likert-type scale items and text responses, the results of which are viewed in percentage summary form and used as the basis for further discussion of topics and reflection on learning processes. At distinct phases of learning, but most especially at the Appraisal phase, it gathers learners' leaning goals, needs and perceptions, reducing the evaluative source of perceptual mismatch.

The figure below enumerates the ICT-based tools which support macro-strategies and correspond to teachers and students' actions and interactions.

\begin{tabular}{|c|c|c|c|}
\hline $\begin{array}{r}\text { Macro-strategies } \\
\end{array}$ & ICT-based tools & Teaching Processes & Learning Processes \\
\hline Expansion of Learning Opportunities; & \multirow{3}{*}{ Resources } & \multirow{3}{*}{ Showcase } & \multirow{3}{*}{ Notice } \\
\hline Activation of Intuitive Heuristics & & & \\
\hline Contextualization & & & \\
\hline Contextualization & Announcement & \multirow{5}{*}{ Highlight } & \multirow{5}{*}{ Compare } \\
\hline Reduction of Perceptual Mismatches & Course Info & & \\
\hline Reduction of Perceptual Mismatches & Course Content & & \\
\hline Facilitation of Negotiated Interaction & Forum & & \\
\hline Reduction of Perceptual Mismatches & Poll & & \\
\hline Promotion of learner autonomy & Assignment & Transfer & Integrate \\
\hline
\end{tabular}

Figure 4. ICT-supported Macro-strategies and Pedagogical/ Epistemological Events

\subsection{Proto-syllabus}

This section illustrates the contents of a proto-syllabus, a seminal workplan drawn out of the selection, implementation and evaluation of tasks by both the teacher and learners during the actual teaching-learning process itself to arrive at continuous significant learning (Fink 2001), for which meta-learning, i.e., learning-how-to-learn, is crucial. It uncovers learners' perceptions of objectives, task content and procedures, learner contributions in terms of actual conditions and resources, which, while revealing deep learning ${ }^{3}$, have the “potential to generate formative criteria for the users' selection and design of new tasks" (Breen, 1989, p. 197)

\footnotetext{
${ }^{3}$ Deep learning involves knowing beyond reproducing information; it seeks the transformation of information: from making sense of ideas and information and developing as a person, together with others by monitoring the development of one's own understanding (Entwistle, 2000).
} 
and attentional resources.

Through various teacher-student interactions guided by the task evaluation cycle (Breen, 1989), this proto-syllabus gathers the elements of teaching-learning interactions that support and facilitate low and high order thinking. These interactions include the following:

$>\quad$ To identify learners' objectives, students were asked to examine and identify whether the course objectives delineated in the Course Introduction and elaborated in the Course Content correspond with their learning goals.

$>\quad$ To discover learner criteria for appropriate content and procedures of tasks, students were involved in deciding on what shall be done "on what content for what period of time and by which procedural routes (Breen, 1989, p. 200). They decide on the topic they wish to explore and complete a creative project about it; they engage in ICT-based discussions and observe how their peers work upon tasks. Their completed creative projects and the processes of interactions between students are recorded and stored in the ICT-based Assignment and the Forum, respectively.

$>\quad$ To involve students in relating tasks to the wider teaching-learning processes --which implies, among them, the knowledge of functions and responsibilities of members of the group-- students were asked to reconsider, observe and demonstrate "their own prior assumptions about their rights and duties in classroom learning, the potential contributions of the other people in the classroom...." (Breen, 1989, p. 201) by suggesting web resources that contribute to the completion of creative projects. The ICT-based Resources store and record these contributions.

Drawing on the data gathered from the task evaluation cycle within the GP framework, the following section delineates the elements of a proto-syllabus of a Business English course. It reveals learners' criteria for progress, awareness of knowledge and productive learning strategies and approaches, and their proactive attitude towards the learning situation (a personality that ensures continuous learning) and the resources within it.

Objectives: To be familiar with concepts, skills and competencies --associated with innovative management in a fast changing business environment-- which are demonstrable in my capacity to transfer classroom-acquired experiential knowledge in tasks similar or related to planning and marketing new products (e.g., writing training course leaflet, giving product presentation, writing press release, etc.).

Content: Technology, Food, Pet Accessories, Fashion and Grooming, House décor, Home Appliance

Procedures of Tasks: Contained in a GP framework, procedures of tasks range from low to high order thinking which lead students to completing creative projects and developing relevant productive skills (or meta-cognitive skills): identification of concepts, description of ideas, classification, application, comparison, evaluation, interpretation, differentiation, construction, and illustration.

- Identification of concepts: level of thinking that recognizes concepts and features of a writing/speech genre

- Description: level of thinking that clarifies ideas to be communicated to another

- Classification: level of thinking that organizes concepts into types

- Application: level of thinking that seeks to connect ideas with a different context

- Comparison: level of thinking that examines differences between two or more concepts

- Evaluation: level of thinking that calculates and judges the value/s of concepts and/or ideas

- Interpretation: level of thinking that expresses one's own ideas about the perceived problems and solutions through creative projects

- Differentiation: level of thinking that shows difference/s of concepts

- Construction: level of thinking that creates a new idea out of varied concepts

- Illustration: level of thinking that expresses concepts and ideas through images

Learner Contributions: They include web materials uploaded onto the ICT-based Resources which record and store websites relevant to completing distinct creative projects (e.g., training course leaflets, press release, 
product descriptions, etc.).

\section{In a Nutshell: ICT-supported Epistemological Spectrum}

Knowing is distinct from understanding, from evaluating, from creating. It is the foundational level of understanding, and it accrues from receiving transmitted information from teachers. Understanding develops from knowing; and from understanding (which is followed by close analysis and synthesis), communication of the understood knowledge ensues through creation (i.e., completing creative projects). These hierarchical cognitive processes delineated in Bloom's taxonomy of cognitive educational goals (Anderson, 2001) constitute the foundation of learning within a Genre-based pedagogy ${ }^{4}$, allowing for significant learning -an approach to learning which calls for intentional understanding of target knowledge through the pedagogical scaffoldings provided by the teacher (showcasing, highlighting, transferring) to arrive not only at simple knowledge, but at a personal transformation. After all, when students invest something of themselves (e.g., mental efforts), they don't just learn facts, but the underlying processes of arriving at target knowledge; and furthermore, upon reflection, the value of created knowledge, an expression of high order thinking which although indefinable, is recognizable (Resnick, 1987). They are understood (not simply known) by experientially hearing and seeing --going through-- the whole epistemological spectrum - identification, description, classification, application, illustration, interpretation, comparison, differentiation, evaluation, construction. Corresponding to Deliberate learning processes (i.e., noticing, comparing, integrating), they may be alternatively referred to as meta-cognitive strategies defined as the knowledge of what one knows useful for addressing problems (Flavell, 1976). Observable, they are measurable through distinct ICT-based tools: Announcement, Course Info/Content, Forum, Resources, Assignment, and Poll, characteristics of each (cf. previous section) provide support to students as they engage in various levels of knowing --from low to high order thinking.

The figure below summarizes the various cognitive levels (from low to high order thinking) and the teaching-learning processes associated with them. It also shows the ICT-based tools that support the processes and the epistemological spectrum, i.e., the range of knowing within ICT-supported language learning. A pedagogical model within which both high and low achievers may be trained, it exemplifies a tool for professional development programs which seek to achieve equitable education for all students (Zohar \& Dori, 2003).

\begin{tabular}{|c|c|c|c|c|c|c|}
\hline & Cognitive Level & $\begin{array}{l}\text { Teaching } \\
\text { Processes } \\
\end{array}$ & $\begin{array}{l}\text { Learning } \\
\text { Processes }\end{array}$ & $\begin{array}{c}\text { Significant } \\
\text { Learning }\end{array}$ & $\begin{array}{c}\text { Epistemological } \\
\text { Spectrum }\end{array}$ & ICT-based Tools \\
\hline 1 & Recall & \multirow{3}{*}{ Showcasing } & \multirow{3}{*}{ Noticing } & \multirow{2}{*}{$\begin{array}{l}\text { Foundational } \\
\text { Knowledge }\end{array}$} & Identification & $\begin{array}{c}\text { Course } \\
\text { Info/Content }\end{array}$ \\
\hline 2 & Understand & & & & Description & Forum \\
\hline 3 & Apply & & & \multirow{3}{*}{ Application } & Application & \\
\hline 4 & Analyze & \multirow{2}{*}{ Highlighting } & \multirow{2}{*}{ Comparing } & & Differentiation & \\
\hline 5 & Evaluate & & & & Evaluation & Resources/Poll \\
\hline \multirow{4}{*}{6} & \multirow{4}{*}{ Create } & \multirow{4}{*}{ Transferring } & \multirow{4}{*}{ Integrating } & Integration & Construction & Assignment \\
\hline & & & & Human Dimension & & \\
\hline & & & & Caring & & \\
\hline & & & & $\begin{array}{l}\text { Learning how to } \\
\text { learn }\end{array}$ & & \\
\hline
\end{tabular}

Figure 5. ICT-supported Epistemological Spectrum

\section{References:}

Anderson, L., \& Krathwohl (Eds.). (2001). A taxonomy for learning, teaching, and assessing: A revision of Bloom's taxonomy of educational objectives. New York: Longman.

Bailey, K. M. (2001). Action research, teacher research and classroom research in language teaching. In M. Celse-Murcia (Ed.), Teaching English as a second or foreign language (pp. 489-498), USA: Heinle and Heinle.

\footnotetext{
${ }^{4}$ It is a mode of teaching and learning which, in supporting Deliberate Learning, takes into account Schmidt's (1990) Noticing Hypothesis.
} 
Yuvienco, J. C.

Bloom, B. S. (1956). Taxonomy of educational objectives. Boston, MA: Allyn and Bacon.

Breen, M. P. (1985). The social context for language learning- a neglected situation? Studies in Second Language Acquisition, 7(2), 135-158. <http://dx.doi.org/10.1017/S0272263100005337>

Breen, M. P. (1989). The evaluation cycle for language learning tasks. In R.K. Johnson (Ed.) The second language curriculum (pp. 187-206). Cambridge: CUP.

Brock, C. A. (1986). The effects of referential questions on ESL classroom discourse. TESOL Quarterly, 20(1), 47-59. <http://dx.doi.org/10.2307/3586388>

Christie, F. (1999). Genre theory and ESL teaching: A systemic functional perspective. TESOL Quarterly, 4(33), 759-763. <http://dx.doi.org/10.2307/3587889>

Ellis, R. (1997). Second language acquisition. Oxford: Oxford University Press.

Entwistle, N. J. (2000). Approaches to studying and levels of understanding: the influences of teaching and assessment. In J. C. Smart (Ed.), Higher education: Handbook of theory and research (pp.156-218).New York: Agathon Press.

Fink, L. D. (2003). Creating significant learning experiences. San Francisco, CA: Jossey-Bass.

Flavell, J. H. (Ed.). (1976). Metacognitive aspects of problem solving. Hillsdale, NJ: Erlbaum.

Freedman, A. (1999). Genre theory and ESL teaching: Beyond the text: Towards understanding the teaching and learning of genres. TESOL Quarterly, 4(33), 764-767. <http://dx.doi.org/10.2307/3587890>

Giltrow, J. (1995). Genre and the pragmatic concept o background knowledge A. Freedman \& P. Medway (Eds.), Genre and the new rhetoric (pp. 155-180). London: Taylor \& Francis.

Giltrow, J., \& Valiquette, M. (1994). Genres and knowledge: Students' writing in the disciplines. In A. Freedman \& P. Medway (Eds.), Learning and teaching genre (pp.47-62). Portsmouth, NH: Boynton/Cook.

Kumaravadivelu, B. (1991). Language learning tasks: Teacher intention and learner interpretation. ELT Journal, 45(2), 98-107. <http://dx.doi.org/10.1093/elt/45.2.98>

Kumaravadivelu, B. (1994). The postmethod cndition: Emerging strategies for second/foreign language Teaching. TESOL Quarterly, 1(28), 27-48. <http://dx.doi.org/10.2307/3587197>

Murphy, J. (2001). Reflective teaching in ELT. In M. Celse-Murcia (Ed.). Teaching English as a second or foreign language (pp. 499-514), USA: Heinle and Heinle.

McNiff, J., Lomax, P., \& Whitehead, J. (2003). You and your action research project (2nd ed.). New York, USA: Routledge Falmer.

Resnick, L. (1987). Education and learning to think. Washington, DC: National Academy Press.

Schmidt, R. (1990). The role of consciousness in second language learning. Oxford Journals Humanities, Applied Linguistics, 11(2), 129-158. <http://dx.doi.org/10.1093/applin/11.2.129>

Schmidt, R. (Ed.) (1995). Attention and awareness in foreign language learning. Honolulu, HI: University of Hawai i, Second Language Teaching \& Curriculum Center (Technical Report No. 9).

Widdowson, H. G. (1990). Aspects of language teaching. Oxford: Oxford University Press.

Yuvienco, J. C. (2006). A case study: Exploring the role of computer-mediated tools in fostering learner autonomy among G5-G7 students of English in Taiwan. Paper presented at the Proceedings of the 4th International Conference of APAMALL and 10th International Conference of ROCMELIA on Online English Test and Instruction.

Yuvienco, J. C. (2007). An educational framework for blended learning within foreign language education. In Ch. Merkelbach (Ed.), Gemischte Lehr- und Lernformen in Fremdsprachenunterricht (pp.161-184). Aachen: Shaker Verlag.

Yuvienco, J. C. (2010). Tandem teaching in an ICT-supported learning environment. In Ch. Merkelbach and Vagios, V. (Eds.), Critical approaches to computer-assisted language and literature teaching (pp. 139-154) Aachen: Shaker Verlag.

Zohar, A. (2003). Higher order thinking skills and low-achieving students: Are they mutually exclusive? The Journal of the Learning Sciences, 12(2), 145-181. <http://dx.doi.org/10.1207/S15327809JLS1202_1> 